\title{
Intelligent compaction practice and development: a bibliometric analysis
}

\author{
Donghai Liu, Youle Wang, Junjie Chen and Yalin Zhang \\ State Key Laboratory of Hydraulic Engineering Simulation and Safety, \\ Tianjin University, Tianjin, China
}

\begin{abstract}
Purpose - The purpose of this paper is to provide insights into the current practice, challenges and future development trends of intelligent compaction (IC) technology from a bibliometric perspective.

Design/methodology/approach - A bibliometric analysis on IC-relevant studies is presented. Through this quantitative manner, insights into the current IC research practice and development trends have been derived from the perspectives of publications and citations, spatial distribution, knowledge construction, structural variations, existing problems, and conclusions and recommendations.

Findings - Currently, IC applications are confronted with the issues of intelligent compaction measurement values (ICMVs) applicability, autonomous control, specifications and applications. To address the issues, three potential research directions are identified: a comprehensive ICMV measurement system that is designated for single layer analysis; autonomous control mechanisms with integrated management capabilities that can efficiently collaborate all stakeholders; and a standardized application workflow and the cost-benefit evaluation of IC in the context of the full life cycle.

Research limitations/implications - The literature used in this paper is collected from the Web of Science. Although the database covers almost all the important publications in IC field, studies not indexed by the database are not considered.

Originality/value - This research quantitatively analyzes the current IC practice and development trends from the perspectives of bibliometric analysis. It provides an overview of the knowledge construction and development of IC technology. The discussions about the problems and the suggested solutions can be useful for those interested in this field.
\end{abstract}

Keywords Knowledge management, Construction, Project management, Information and communication technology (ICT) applications

Paper type Literature review

\section{Introduction}

In recent years, the extensive construction of highways brought great challenges for quality management, because these projects are required to achieve high-standard construction quality in limited time with inefficient quality control (QC) techniques. Traditional compaction $\mathrm{QC}$ practice, which relies on on-site supervision and post-compaction spot tests, has the following limitations. First, the manner of manual supervision is prone to yield unreliable results. Second, the spot tests may interfere with the subsequent construction operation. Third, using limited test samples (less than 1 percent) to represent the compaction quality of the entire working zone often leads to biases (Cai et al., 2019).

Intelligent compaction (IC) or continuous compaction control (CCC) has emerged as a technology to overcome the above limitations, which provides a promising solution to innovate

(C) Donghai Liu, Youle Wang, Junjie Chen and Yalin Zhang. Published by Emerald Publishing Limited. This article is published under the Creative Commons Attribution (CC BY 4.0) licence. Anyone may reproduce, distribute, translate and create derivative works of this article (for both commercial and non-commercial purposes), subject to full attribution to the original publication and authors. The full terms of this licence may be seen at http://creativecommons.org/licences/by/4.0/legalcode

This research was supported by the National Natural Science Foundation of China (Nos 71572127 and 51979189) and National Key Research and Development Program of China (No. 2018YFC0406903).
Intelligent compaction practice

Received 23 May 2019 Revised 21 September 2019 14 November 2019 Accepted 22 November 2019

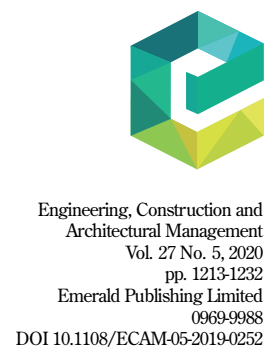


ECAM

27,5

\section{4}

Figure 1.

Architecture

of IC technology current QC practice for soil and pavement compaction. IC technology sets up an integrated managerial mechanism for information sharing and collaboration between operators, contractors, supervisors and the owner by adopting the architecture shown in Figure 1:

(1) The real-time monitoring module continuously provides the intelligent compaction measurement values (ICMVs) for $\mathrm{QC}$, which are derived from a rapid assessment model based on the vibration response and running status. In this module, an accelerometer is mounted in the drum, and, optionally, an infrared sensor can also be attached for temperature monitoring in asphalt pavement projects.

(2) The Global Navigation Satellite System module continuously tracks the position of rollers, based on which the trajectories, rolling passes and roller velocities are derived.

(3) The remote-control module allows all stakeholders in a project to monitor the compaction process online at anytime and anywhere. Based on the Geographic Information System (GIS), the real-time compaction information is visualized on the user interface.

(4) The adaptive adjustment module is the last step in the control loop, which adaptively adjusts the roller operation status to the objective ICMVs for achieving the desired compaction outcomes. The adjustment can be either performed manually by roller operators or automatically by an onboard control unit.

In 1970s, the concept of ICMVs was first proposed (Thurner and Sandstrom, 2000). After years of development, IC has evolved into an emerging multidisciplinary area that involves signal processing, remote sensing, wireless communication, feedback controls and adaptive adjustment. Extensive studies and case studies (Adam et al., 2007) have demonstrated the feasibility of IC technology in various types of soil materials with different compositions and gradations. With the successful applications in cement-fiber modified soil, cement-stabilized macadam, roller compacted concrete and asphalt mixtures, IC has become an important part of the $\mathrm{QC}$ procedure (see Table I). European countries have started issuing relevant specifications for IC applications. The abbreviation of the Department of Transportations in the USA is US Dots. Has also been working on expanding the IC applications by coming up with a unified standard (Veta, 2018).

IC provides intuitive information of the compaction process to guide the rolling operations of the driver, which can effectively reduce the occurrence of under compaction or over compaction. Due to this merit, IC has been widely accepted as an effective QC technique for pavement compaction (Kuenzel et al., 2016; Xu and Chang, 2016; Yao et al., 2018). However, although attempts have been continuously made to apply IC in quality assurance (QA)

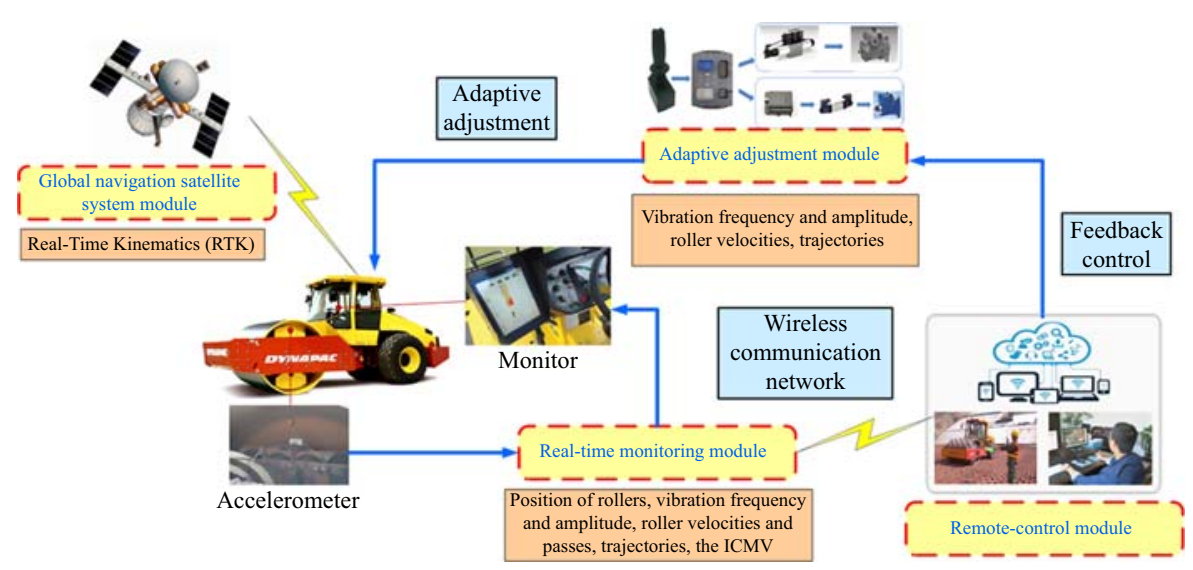




\begin{tabular}{lllll}
\hline No. & Source & Specification & Range & Calibration \\
\hline 1 & Finland & Tielaitos 91 & Subgrade & Plate Load Test (PLT), $\rho$ \\
2 & Austria & RVS 8S.02.6 (1999) & Base & $R>0.7$ ( $R>0.6$ in Sweden) \\
3 & ISSMGE & TC3 (2005) & Subbase & \\
4 & Sweden & BYA 92, ATB Vg 2005 & Base & \\
& & & Subbase \\
5 & Germany & ZTVE StB/TP BF-StB 94 & Subgrade & \\
6 & United & FHWA Generic Soils IC Specification 2014 & Subgrade & Dynamic Cone Penetrometer \\
& States & FHWA Generic Asphalt IC Specification 2014 & Base & (DCP) \\
& & AASHTO PP81-14 IC Specification 2016 & Subbase & Light Weight Deflectometer \\
& & Pavement & (LWD) \\
& & & GeoGauge, $\rho$ \\
7 & China & TB 10108-2011 & Subbase & \multicolumn{2}{c}{$\rho$, Compactness } \\
& Q/CR 9210-2015 & & $R>0.7$ \\
& JT/T 1127-2017 & &
\end{tabular}

Note: The automatic feedback control of vibration amplitude or frequency is not permitted during calibration or quality assurance in European countries

Table I. Introduction of specifications

(see Table II) (Beainy et al., 2012; Cai et al., 2019; Rinehart et al., 2012), the industry is still reluctant to totally replace current spot test-based acceptance manner with IC because of the potential risks brought by the uncertain correlation between compaction quality and ICMVs (Yoon et al., 2018). Therefore, the adoption of IC in QA is not as optimistic as that in QC.

This paper provides insights from a bibliometric perspective into the current practice, challenges and future development trends of IC technology. First, through this quantitative manner, an insight into the current IC research practice in the past twenty years has been derived from the perspectives of publications and citations, spatial distribution, knowledge construction and structural variations. Second, the clusters of the citation links are reviewed from the bibliometric statistics. The findings can promote the understanding of the development for IC applications, which can overcome the subjectivity of traditional empirical methods. Third, the challenges that confront the IC technology have been identified. To tackle these challenges, directions for future research have also been pointed out. All acronyms and abbreviations have been listed in the glossary section.

\section{Bibliometric statistics}

Bibliometrics is a powerful tool to explore the knowledge domains and reveal the hot topics of emerging technologies. On one hand, this tool can yield a quantitative assessment for the

\begin{tabular}{|c|c|c|}
\hline Aim & Literatures & Related results \\
\hline \multirow[t]{4}{*}{$\mathrm{QC}$} & $\mathrm{Xu}$ and & They presented an material-machine-information and human-decision integrated \\
\hline & Chang (2016) & system for adaptive $\mathrm{QA} / \mathrm{QC}$ based on IC technology \\
\hline & $\begin{array}{l}\text { Kuenzel et al. } \\
(2016)\end{array}$ & $\begin{array}{l}\text { A real-time path planning system for rollers was introduced, based on belief-desire- } \\
\text { intention software agents }\end{array}$ \\
\hline & Yao et al. (2018) & A management platform was developed for the unmanned compaction of the impact \\
\hline \multirow[t]{3}{*}{ QA } & $\begin{array}{l}\text { Beainy et al. } \\
(2012)\end{array}$ & $\begin{array}{l}\text { The statistical QA based on percent within limits could be a tool for the QA } \\
\text { depending on IC technology }\end{array}$ \\
\hline & $\begin{array}{l}\text { Rinehart et al. } \\
\text { (2012) }\end{array}$ & $\begin{array}{l}\text { The roller-integrated CCC on earthwork compaction QA has been incorporated into } \\
\text { specifications in Germany, Austria and Sweden }\end{array}$ \\
\hline & Cai et al. (2019) & $\begin{array}{l}\text { They developed a web tool to augment the random sampling process in field QA } \\
\text { practice by incorporating the spatial pattern of samples from ICMVs }\end{array}$ \\
\hline
\end{tabular}

Table II. Application of IC technology for $\mathrm{QC} / \mathrm{QA}$ 
ECAM

27,5

1216

researched domain by analyzing the provided literatures with statistics, which can overcome the subjectivity brought by manual investigation. On the other hand, the knowledge map generated by the method can provide an intuitive manner for researchers to better understand the inner structure and the evolvement of the research domain. This research performed a bibliometric analysis on IC-relevant publications in the past twenty years based on CiteSpace (Chen, 2016) and ArcGIS.

The literature used in this research came from the core collection of Web of Science. A total of 160 publications (see Table III) were included, which were first selected by relevance filtering and then further extended through forward-citation links. All of the literature was published from 1999 to 2018 (till October 1, 2018), covering three different topics, i.e. "Intelligent Compaction," "Continuous Compaction Control" and "Rollerintegrated." Although the coverage may be a limitation, the database covers almost all the important publications in the field, which can reflect the current practice of IC technology.

\subsection{Publications and citations}

Figure 2 shows the temporal distribution of publications and citations in the area of IC. Both the number of publications and citations have been steadily increasing in the past twenty years. The significant growth of research efforts on IC reflects the urgent need for an innovative compaction control method. For further analysis, the publications were divided into different categories based on the region of origin and the publication date. From Figure 3, we can see studies on IC were mainly carried out in developed countries such as the USA, and European countries. Recently, with the increasing research inputs, China is becoming an emerging subject in IC studies. Publications from other countries have also increased in the past two decades.

\subsection{Spatial distribution of IC studies}

To study the spatial distribution of IC studies quantitatively, an analysis based on COV and geographical detectors (Wang et al., 2010) (e.g. statistic q) was presented. First, using the

Table III.

Summary of the literature collection (unit: record)

\begin{tabular}{lcccccc}
\hline Collection & Duration & Articles & Proceedings papers & References & Authors & Institutions \\
\hline Topic search & $1999-2018$ & 104 & 56 & 2,052 & 585 & 257 \\
\hline
\end{tabular}

Figure 2.

Temporal distribution of publications and citations

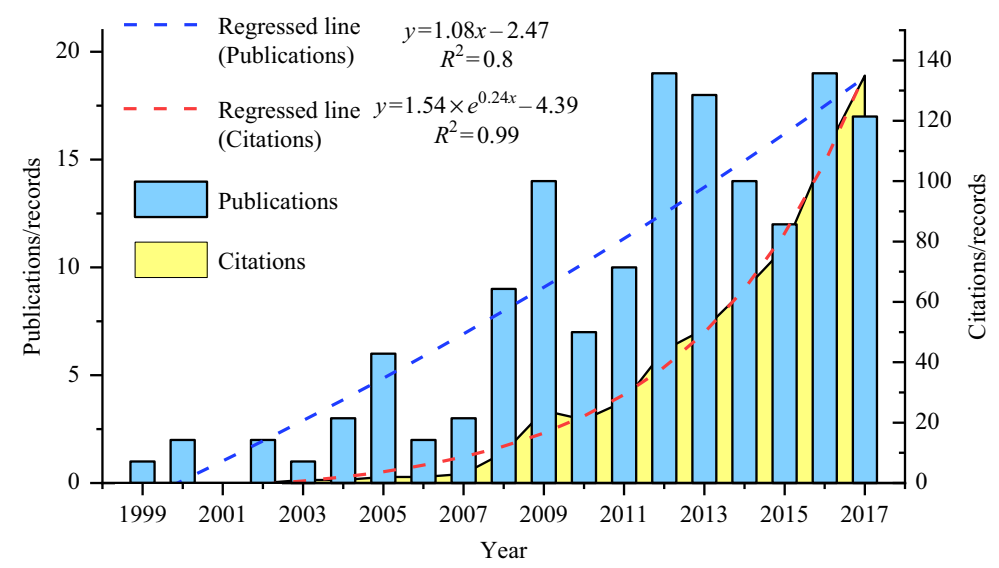




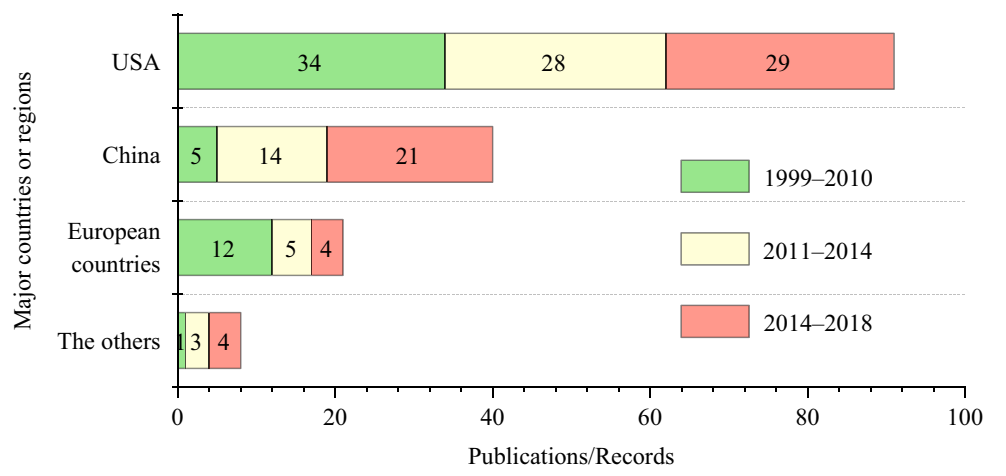

Intelligent
compaction
practice

1217

Figure 3.

Number of publications in different periods

natural breakpoint method, the collected IC-relevant literature was divided into five clusters (Yan et al., 2018) according to the quantities of literature in terms of countries, institutions, authors and publishers. Second, $C O V$ and $q$ (range from 0 to 1 ) were derived based on the clustering results, with which the spatial distribution can be identified. It is noteworthy that the larger the $C O V$ (or $q$ ), the more remarkable the spatial variation.

The results (listed in Table IV and Figure 4) demonstrated a significant spatial variation of IC studies, implying that the key technologies of IC might have been monopolized by only a few countries or institutions.

Using ArcGIS, the evolution of the spatial distribution of IC studies is visualized in Figure 5. The distribution of research groups in the USA and European countries remained relatively stable. The early-stage distribution of IC publications showed a pattern of polarization, where the cooperation was mainly between a few developed countries in the Western world. Recently, with the emergence of new research groups in Asia (especially in China), international cooperation became more frequent in the global scale. The evolvement in Asian area showed a pattern of expansion from east costal area to the southwest. In contrast, the standard deviation ellipse in Europe depicted a sign of shrinkage, suggesting that the promotion of IC was not that successful. In general, the spatial distribution of IC studies is experiencing some dramatic changes, and a pattern of mutual development in multiple regions is being formed. However, the uneven distribution of related studies still needs to be mitigated to promote the application of $\mathrm{IC}$ in different countries and regions.

\subsection{Knowledge construction}

The co-citation network is a knowledge map that rebuilds the knowledge in the free state for a comprehensive overview of IC studies. The network in Figure 6 consists of three clusters, i.e. ICMVs, influence factors, and monitoring systems and their applications. In general, the homogeneity of this network was statistically acceptable, e.g. the silhouette (larger than 0.5) and modularity $Q$ (larger than 0.3).

\begin{tabular}{|c|c|c|c|c|c|c|c|c|}
\hline \multirow[t]{2}{*}{ Source } & \multicolumn{5}{|c|}{ Records in the different data clusters (records) } & \multirow[b]{2}{*}{$\mathrm{COV}$} & \multirow[b]{2}{*}{$q$} & \\
\hline & The most & More & Medium & Less & The least & & & \\
\hline Countries/regions & 1 & 1 & 4 & 3 & 9 & 2.44 & 1.00 & \\
\hline Institutions & 2 & 6 & 8 & 25 & 75 & 1.27 & 0.96 & Table IV. \\
\hline Authors & 3 & 8 & 21 & 48 & 266 & 1.13 & 0.96 & Spatial distribution \\
\hline Publications & 2 & 3 & 8 & 15 & 73 & 1.16 & 0.98 & of IC studies \\
\hline
\end{tabular}


ECAM

27,5

\section{8}

Figure 4.

Spatial distribution of (a) countries and

(b) institutions

in this field

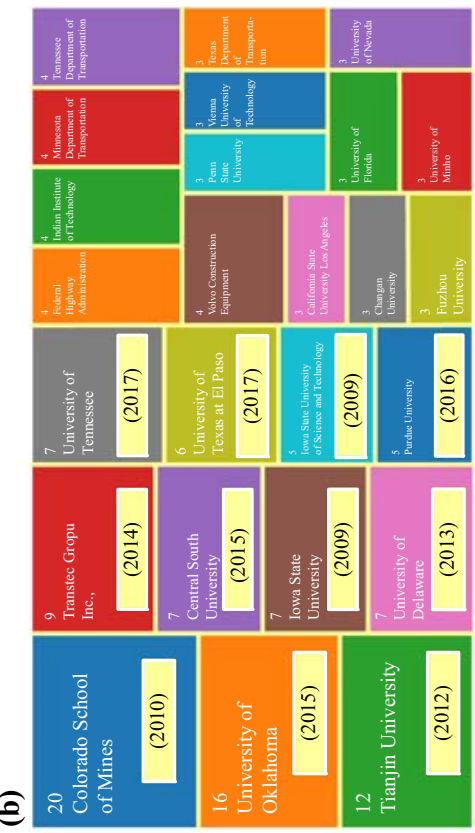

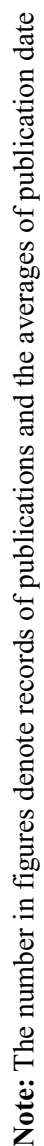




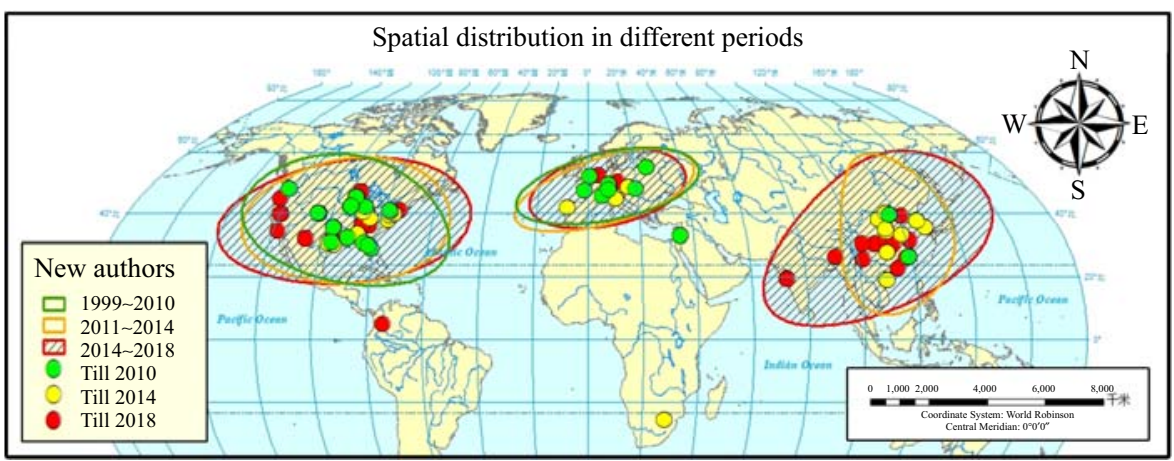

Intelligent compaction practice

1219

Figure 5.

Spatial distribution in different periods

(a)

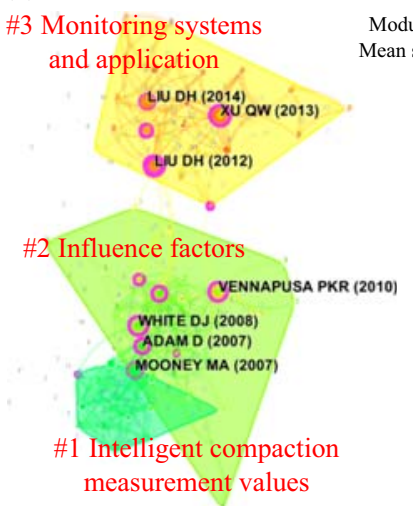

(b)

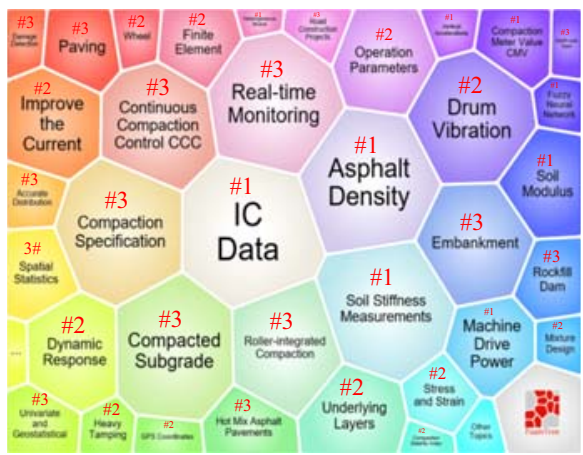

Notes: (a) Co-citation network; (b) keyword clusters

Figure 6. Knowledge construction of IC studies

2.3.1 Intelligent compaction measurement values (2004 2009). Currently, the ICMVs, which are derived from vibratory acceleration analysis, are widely accepted for compaction quality assessment. The US DOTs (FHWA, 2017) divided existing ICMVs into five levels (see Table V), according to their correlation with physical properties of materials, effectiveness in the double jump stage and applicability to gain layer-specific behaviors.

2.3.1.1 Level 1: empirical solutions based on frequency responses. In this level, relevant studies mainly focus on the dynamic frequency response of the drum. Specifically, the ICMVs are defined as an empirical function of the correlation between harmonic components and compaction quality, e.g. the vibratory frequency reactive model and the oscillation frequency reactive model.

Typical representatives for the vibratory frequency reactive model include $C M V$ and $R M V, C C V, T H D$ and $F_{t}$. Among them, the $C M V$ (Thurner and Sandstrom, 2000) is a ratio of the first and fundamental harmonic content, which is often used with the $R M V$ (the ratio of the half and fundamental harmonic content) to detect the "double jump." The CCV (Xu and Chang, 2013) is an improved index of $C M V$ by considering the sub-harmonic components. The THD (Mooney et al., 2005) extends the harmonic components considered by the CMV to a full-band range. The $F_{t}$ (Furuya and Fujiyama, 2011), which takes the roller deadweight into accounts, introduces the external load into the model. 
ECAM

27,5

1220

Table V.

Introduction of ICMVs

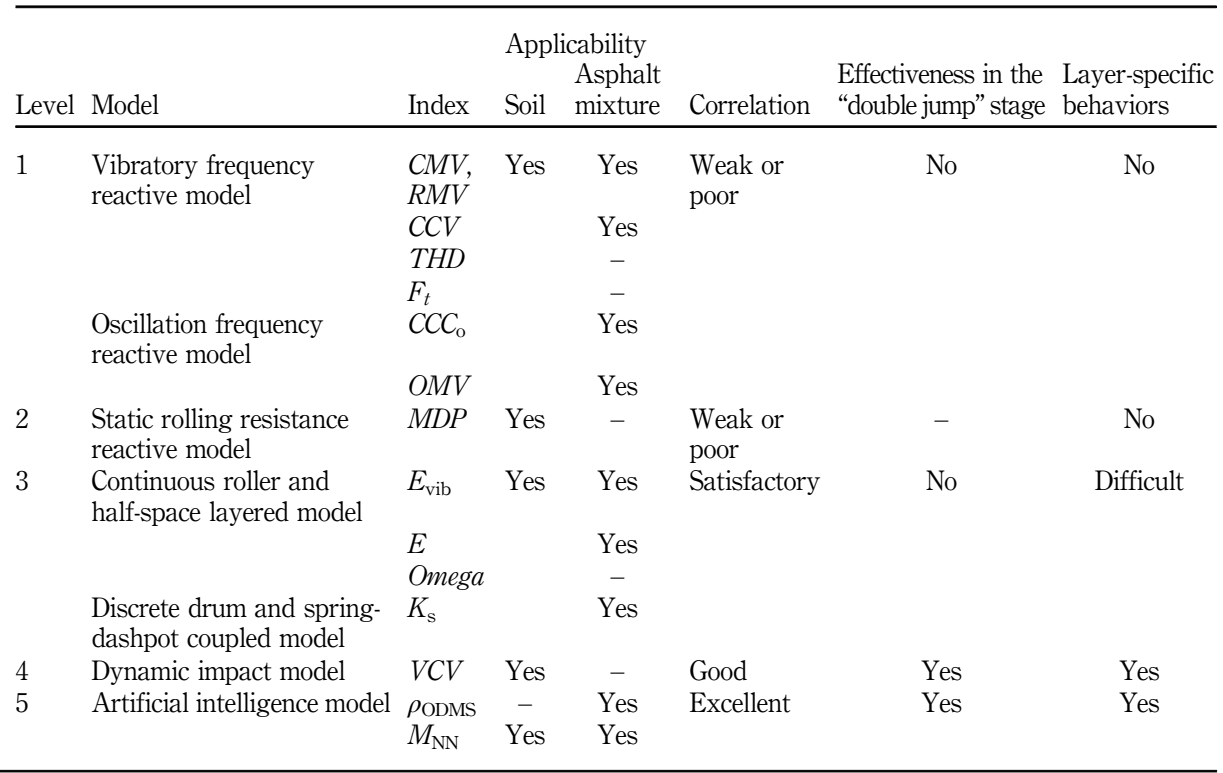

For oscillatory roller compaction, the $C C C_{\mathrm{o}}$ and $O M V$ are the most widely used. The $C C C_{\mathrm{o}}$ (Pistrol and Adaml, 2018) is defined as the area of the eight-shape plots that is enclosed by the chronologically connected pairs of the variation acceleration of the drum center. The OMV (Thurner and Sandstrom, 2000) is defined as a ratio of amplitudes of different horizontal acceleration harmonic components, which are collected by a sensor mounted at the center of the drum.

ICMVs in this level are based on the frequency response analysis of the drum. Due to the non-linearity of the contact condition and constitutive relation, the recognition of frequency responses and their applicability still depend on project experience, and lack theoretical support.

2.3.1.2 Level 2: empirical solutions based on energy and rolling resistance. The level-two ICMVs are derived from the correlation between the energy dissipation caused by rolling resistance and the compaction quality. A representative of level-two ICMVs is MDP (White and Thompson, 2008), which provides an approach to assess the average compaction quality from the perspective of energy transmission. However, this type of ICMVs still lacks the support of rigorous mathematic derivation, and relies on empirical estimation.

2.3.1.3 Level 3: simplified static mechanical solutions. Unlike the first two levels, levelthree ICMVs are derived from rigorous theoretical basis. Two different types of mechanical models are usually used to deduce the ICMVs, i.e. the continuous roller and half-space layered model and the discrete drum and spring-dashpot coupled model.

The former is based on continuous static analysis, which estimates the compaction quality by simplifying the pavement system to a half-space, and assuming that the acceleration component is ignorable. This type of ICMVs include the vibration modulus $E_{\mathrm{vib}}$ (Mooney and Rinehart, 2009), which is described by the slope of the relationship between the displacement and the force, unit compaction energy $E$ (Liu et al., 2015) and total energy output $O_{\text {mega }}$ (Adam et al., 2007).

Based on the discrete dynamic analysis, the drum and spring-dashpot coupled model describes the compacted materials as an equivalent elastic body that is modeled with 
elastic spring and dashpot in parallel. As a further simplification, a stiffness index $K_{\mathrm{S}}$ at the peak of the displacement curve (Anderegg and Kaufmann, 2004) is adopted to represent the compactness.

However, the simplifications and assumptions made by these models might bring some issues. For example, ignoring the acceleration component in the static assumption will result in distorted outcomes. In addition, the estimation of phase lags is a challenge for the springdashpot coupled model, which is difficult to be directly detected because of electromagnetic shielding, cross-wise sensitivity and temperature effect. This type of ICMVs might not work properly in the double jump stage when the roller and the compacted materials lose the contact to each other.

2.3.1.4 Level 4: dynamic mechanical solutions. The level-four ICMVs take the impact effect between the drum and the compacted materials into account, and define the drum acceleration as a type of resistance index - VCV (Zhang et al., 2015). By analyzing a closedloop of the drum, exciting force, reactive force and the pavement system, the compaction quality is assessed in real time.

ICMVs in this level can effectively address the "double jump" issue, and gain layer-specific behaviors of the compacted materials. However, these indices require periodical calibration to adapt to the varying conditions and phase lags in the field.

2.3.1.5 Level 5: dynamic mechanical solutions based on AI. The level-five ICMVs aim to realize autonomous compaction control under complex conditions by combining dynamic mechanical solutions with AI algorithms. Although it is difficult to fuse the two different models because of the limited understanding of ICMVs, some research efforts have been made, e.g. the predictive density $\rho_{\text {ODMS }}$ (Minchin et al., 2008) based on the AI statistical model and the estimated modulus $M_{\mathrm{NN}}$ (Singh et al., 2015) based on the AI frequency identification. In the future, the level-five ICMVs would be an important topic for IC researchers.

2.3.1.6 Other indices. In recent years, some new ICMVs have been developed (see Table VI). For example, the $C I$ (Kassem et al., 2012) introduces an effectiveness factor to evaluate the constraint conditions of the mat beneath the roller. The SCV (Zhang et al., 2017) provides an approach to assess the compaction quality based on acoustic wave detection. The $C F$ (Hua et al., 2018) describes the waveform changes in the vibration acceleration, which was relevant to the compactness. The CSD (Kimmel and Mooney, 2011) is a measurement of the pad strain to assess the soil stiffness. However, the applicability of these indices still needs to be further validated.

2.3.2 Influencing factors (2006 2014). 2.3.2.1 Contacting status. During the vibratory compaction process, the contacting status between the drum and the compaction materials typically goes through the following five stages (Adam et al., 2007), i.e. continuous contact, partial uplift, double jump, rocking motion and chaotic motion. The continuous contact is favorable to improving the compactness because of a strong linear correlation, although it

\begin{tabular}{|c|c|c|c|c|c|c|c|c|}
\hline Level & Model & Index & $\begin{array}{l}\text { App } \\
\text { Soil }\end{array}$ & $\begin{array}{l}\text { licability } \\
\text { Asphalt } \\
\text { mixture }\end{array}$ & Correlation & $\begin{array}{l}\text { Effectiveness in the } \\
\text { "double jump" stage }\end{array}$ & $\begin{array}{c}\text { Layer-specific } \\
\text { ability } \\
\end{array}$ & \\
\hline 1 & $\begin{array}{l}\text { Effectiveness factor model } \\
\text { Acoustic wave frequency } \\
\text { reactive model }\end{array}$ & $\begin{array}{l}C I \\
S C V\end{array}$ & $\begin{array}{c}- \\
\text { Yes }\end{array}$ & $\begin{array}{c}\text { Yes } \\
-\end{array}$ & Weak or poor & No & No & \\
\hline & $\begin{array}{l}\text { Vibratory frequency } \\
\text { reactive model }\end{array}$ & $C F$ & Yes & - & & & & $\begin{array}{r}\text { Table VI. } \\
\text { New ICMVs in }\end{array}$ \\
\hline 2 & Pad strain model & CSD & Yes & - & Weak or poor & No & No & recent years \\
\hline
\end{tabular}


ECAM

27,5

1222

only occurs when the soil stiffness is low. The partial uplift is normally considered as the design condition of conventional rollers. In this stage, the contact between the drum and compacted materials is lost partially (Anderegg and Kaufmann, 2004). With the increase of high-frequency harmonic components, the correlation between ICMVs and compactness becomes nonlinear. With the continuous increase of soil stiffness, the probability of the "double jump" rises. The ICMVs will fail to reflect the compaction state properly when the duration of losing contact is greater than the spinning cycle of eccentric block. Thereafter, the drum enters uncontrollable states called rocking, and chaotic motion. A similar process (Pistrol and Adaml, 2018) also occurs to the oscillation compaction.

2.3.2.2 Phase lags. Due to the existence of damping effect, phase lags (Mooney and Rinehart, 2007) is commonly observed, which is a phenomenon that the drum movement always lags behind the current excitation force with a certain angle. Under a constant excitation force, phase lags decrease with the hardening of the compacted materials. However, because the excitation force increases the effective mass of the whole vibration system, the phase lags under a high excitation force will increase accordingly.

2.3.2.3 Underlying layers. Theoretically, the measuring range of ICMVs is determined by the decay of the stress and strain (Mooney and Rinehart, 2009). However, due to the complicated triaxial characteristics of the compaction loading process, the ICMVs are actually global representatives of the underneath anisotropic materials, which is a major difference than conventional spot tests.

The measurement depth (approximately $0.4 \mathrm{~m}$ to $1.5 \mathrm{~m}$ ), affected by the excitation force and the deadweight of the roller (Rinehart and Mooney, 2009), is generally greater than the pavement thickness. Therefore, the support and constraint condition of the underlying layers should be considered. For example, a layer with small thickness supported by a rigid base would be easier to be compacted, compared with one supported by a flexible base (Schmitt, 2012). Furthermore, the compacted materials normally have larger density when they are close to restricted or semi-restricted longitudinal joints (Kassem et al., 2012).

In view of these problems, the identification of the difference in ICMVs may be a solution of mitigating their negative impacts. For instance, a multiple regression model considering the $C M V$ of underlying layers was recommended to decouple the $C M V$ to each layer (Zhu et al., 2018). Based on a "cylinder deformation modulus" assumption, $\mathrm{Hu}$ (Hu et al., 2017) suggested that the effect of underlying layers might be considered by comparing the difference in $1 / C M V$ s rather than themselves.

2.3.2.4 Soil properties. According to Terzaghi's theory, there are remarkable differences between cohesive and non-cohesive soil (Kimmel and Mooney, 2011), such as the contact stress distribution, contact area and surface deformation during compaction.

In practice, the residual moisture in the soil will produce a high pore pressure, which increases the energy consumption to overcome the shearing and reshaping effect. The moisture content in soils also has an influence on the material stiffness because of the changing effective stress (Meehan et al., 2017).

2.3.2.5 Pavement properties. Unlike soil materials, asphalt mixture exhibits significantly different properties under different temperature. When the temperature of asphalt mixtures is beyond a reasonable range (Kassem et al., 2012), the compacting operation will fail to work properly.

ICMVs are comprehensive characterizations of the overall modulus of the pavement system constituted by multiple layers. As a result, a linear model is inadvisable to simply describe the correlation between ICMVs and the material modulus, if the materials vary remarkably along the vertical direction (Zhu et al., 2018).

In addition, the moisture content, aggregate size and gradation of pavement materials also impact on the pavement compaction assessment. However, they are difficult to be 
accurately quantified in real time due to the limitation of measurements. Therefore, they are generally considered as error sources of the uncertainty (Xu and Chang, 2016).

2.3.2.6 Roller operating status. The roller operating status determines the amount of work done to the compacted materials. The frequency, the size and the direction of excitation force directly affect the measurement depth, and the compaction effectiveness (Adam et al., 2007). High-amplitude vibration with low frequency can improve the compaction effectiveness and measurement depths, but might also loosen and break the particles in the shallow layer, and induce the "double jump." Low-amplitude vibration with high frequency exerts super-harmonic components to the compacted materials, which can effectively concentrate the compaction energy, and prevent the damage under a high-amplitude vibration or a quasi-periodic chaotic motion. However, this vibration status has limited compaction effectiveness.

Owing to the inertia and dissipation of the soil, the resonant frequency of compacted materials (approximately 20-35 Hz) might transfer toward the high-frequency area with the increase of soil stiffness (Mooney and Rinehart, 2007). As shown by Figure 7, the frequency domain with the resonant frequency before and after transferring is divided into three regions, i.e. weakening zone, transition zone and enhancement zone. Therefore, the change of ICMVs might show varying patterns, if the roller operation frequency switches from a lower level to a higher level.

In terms of roller speed, rolling at a high speed will reduce the compaction effort exerted to the materials during each pass, whereas rolling at a lower speed might enlarge the unfavorable running status. In addition, some rollers lack a mechanism to ensure the constant output of vibration frequency and amplitude. As a result, the output parameters of these rollers vary with the change of the throttle and the rolling direction, leading to a fluctuation of ICMVs (Liu and Gao, 2018).

2.3.2.7 Data processing. To mitigate the systematic errors detected during the process of collecting ICMVs, Facas (Facas and Mooney, 2012) introduced a procedure of uncertainty analysis to determine malfunctioning roller measurement systems and the insensitive ICMVs. Nie (Nie et al., 2018) presented two identification methods to distinguish the anomalous data. Facas (Facas et al., 2010) derived a measurement to eliminate the directional dependence from rocking motion. In terms of anisotropy in the spatial distribution of ICMVs, the local average method in the marching direction (Facas et al., 2010) and the spatial average method within a certain range (Graettinger et al., 2012) will be effective solutions.

In addition, a generic GIS platform is needed to manage heterogeneous IC data. The Veta can be an ideal solution to import data from various IC systems to perform standardized viewing, analysis, and reporting. The latest edition of Veta (2018) has supported various cloud services, interactive viewing, data filtering, engineering division, correlation analysis, statistical reporting. It is required as a standardized tool for $\mathrm{QC}$ and is increasingly adopted by US DOTs due to its merits in the compatibility.

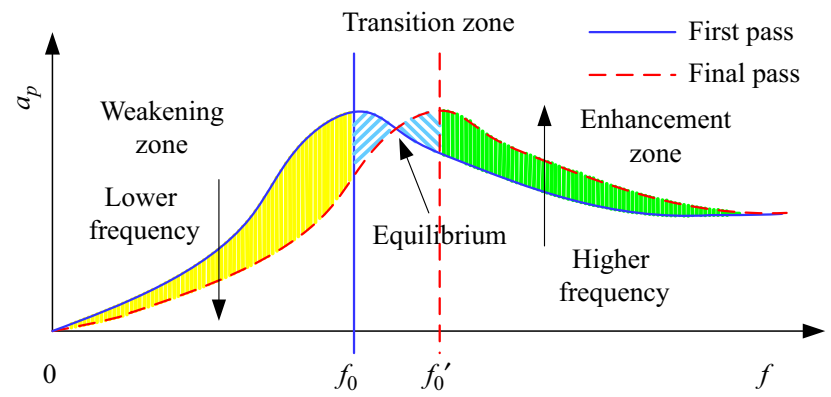

Intelligent compaction practice

1223 
ECAM

27,5

1224

Table VII.

Introduction of monitoring system
2.3.3 Monitoring systems and their applications (2009 2018). Currently, many compaction monitoring systems (see Table VII) have been developed for the IC application.

2.3.3.1 Early-stage systems. Typical early-stage systems include CDS (Geodynamik), CTS (Oloufa, 2002), CRICOM (Pampagnin et al., 1998) and AutoPave (Krishnamurthy et al., 1998). These systems provide basic functionalities for compaction parameters monitoring, e.g. rolling trajectory, direction, speed, passes and lift thickness. They were mainly used for assisting the supervisors to manage the construction process, and remained at a low automation level.

2.3.3.2 IC systems. IC systems realize, to a certain degree, adaptive control of the compaction parameters such as excitation frequency, amplitude and roller speed by introducing ICMVs. These systems include BCM (Bomag) (Kloubert, 2006), ACE (Ammann) (Anderegg et al., 2006), DCA (Dynapac, 2003), CIS (Sakai) (Sakai, 2018), AccuGrade (Caterpillar and Trimble) (Caterpillar, 2007) and Alfa (Obayashi) (Furuya and Fujiyama, 2011). Because such systems are integrated as the auxiliary modules of rollers, the application cost is relatively high.

2.3.3.3 Post-processing systems. These systems use GIS and geostatistics to comprehensively analyze the IC data collected from the entire working zone, which remove technical barriers for large-scale IC applications. Typical post-processing systems include SCAN (Hwang et al., 2012), Veda (Xu and Chang, 2013), CMS (Kassem et al., 2015) and CAWDS (Zhang et al., 2017).

2.3.3.4 Artificial intelligence compaction systems. The abbreviation of the artificial intelligence compaction systems is AI compaction systems. Such as ICA (Singh et al., 2015) and HEMS (Yao et al., 2018), could significantly improve the automation level of construction management by introducing neural network and autonomous driving techniques. However, most of these systems are still under development.

2.3.3.5 Integrated compaction management systems. Based on the concept of modular design, these systems can be customized according to the characteristics of specific projects and user demands. These systems not only provide the roller operators with real-time compaction information, but also set up a mechanism for information sharing and

\begin{tabular}{|c|c|c|c|c|c|}
\hline Type & System & ICMV & $\begin{array}{l}\text { ect } \\
\text { Running status }\end{array}$ & Adaptive control & Integration \\
\hline Original systems & $\begin{array}{l}\text { CDS } \\
\text { CTS } \\
\text { CIRCOM } \\
\text { AutoPave }\end{array}$ & No & Yes & No & No \\
\hline IC systems & $\begin{array}{l}\text { BVC } \\
\text { BCM } \\
\text { ACE } \\
\text { DCA } \\
\text { CIS } \\
\text { AccuGrade } \\
\text { Alfa }\end{array}$ & $\begin{array}{l}E_{\mathrm{vib}} \\
K_{\mathrm{s}} \\
C M V \\
C C V \\
M D P, C C V, C M V \\
F_{t}\end{array}$ & No & $\begin{array}{l}\text { Yes } \\
\text { Yes } \\
\text { Yes } \\
\text { No } \\
\text { No } \\
\text { No }\end{array}$ & No \\
\hline Post-processing system & $\begin{array}{l}\text { SCAN } \\
\text { Veda } \\
\text { CMS } \\
\text { CAWDS }\end{array}$ & $\begin{array}{l}\text { No } \\
\text { Various } \\
C I \\
S C V\end{array}$ & $\begin{array}{l}\text { Yes } \\
\text { Yes } \\
\text { Yes } \\
\text { No }\end{array}$ & No & No \\
\hline $\begin{array}{l}\text { Artificial intelligence } \\
\text { compaction systems } \\
\text { Integrated compaction } \\
\text { management systems }\end{array}$ & $\begin{array}{l}\text { ICA } \\
\text { HEMS } \\
\text { RMSCQ } \\
\text { SmartSite } \\
\text { ACF }\end{array}$ & $\begin{array}{l}M_{\mathrm{NN}} \\
\text { No } \\
C M V, E, T H D \\
\text { No } \\
\text { Various }\end{array}$ & $\begin{array}{l}\text { No } \\
\text { Yes } \\
\text { Yes }\end{array}$ & $\begin{array}{l}\text { No } \\
\text { No } \\
\text { No } \\
\text { Yes }\end{array}$ & $\begin{array}{l}\text { No } \\
\text { Yes }\end{array}$ \\
\hline
\end{tabular}


collaboration between different stakeholders in a project. Typical integrated compaction management systems include RMSCQ (Liu et al., 2016), SmartSite (Kuenzel et al., 2016) and AFC (Xu and Chang, 2016).
Intelligent compaction practice

\subsection{Structural variations}

This section provides a further investigation into the evolvement of the knowledge structure in IC area. In general, the hubs that are highly connected to other nodes or the key points among different groups might have a higher structural centrality. The half-life, which describes the duration of the newer half of the citations, is used to characterize the continuous effect of the node (Chen, 2016). Thus, the above indices were used to measure the value of each node in the co-citation network.

The results are shown in Figure 8, and Table VIII. In Figure 8, the nodes with high centralities (larger than 0.1) were highlighted with magenta circle. In addition, the citation information of a node in different periods was described by a so-called citation tree ring (a color-coded concentric ring) (Chen, 2016).

Cluster no. 1 presented different types of ICMVs, of which the contributions focused on setting up the theoretical basis for applying IC technology. The references with remarkable citation frequency and structural centrality appeared mainly in the early period of the twenty-first century. For instance, the contributions of Mooney (Mooney and Rinehart, 2007) and Adam (Adam and Kopf, 2004) are the improvement of $K_{\mathrm{s}}$ from the perspective of resonance and the review on parameters control methods with different types of rollers respectively. However, relevant studies on ICMVs were recently fallen into a low ebb, which indicated that the theoretical solutions of the ICMV dynamic model and its control methods were still challenging tasks.

Cluster no. 2 was an extension of cluster no. 1. There were tight links between these two clusters in the structure. Four references exhibited higher values as key nodes than the other publications in the cluster. White (White and Thompson, 2008) discussed the effects of

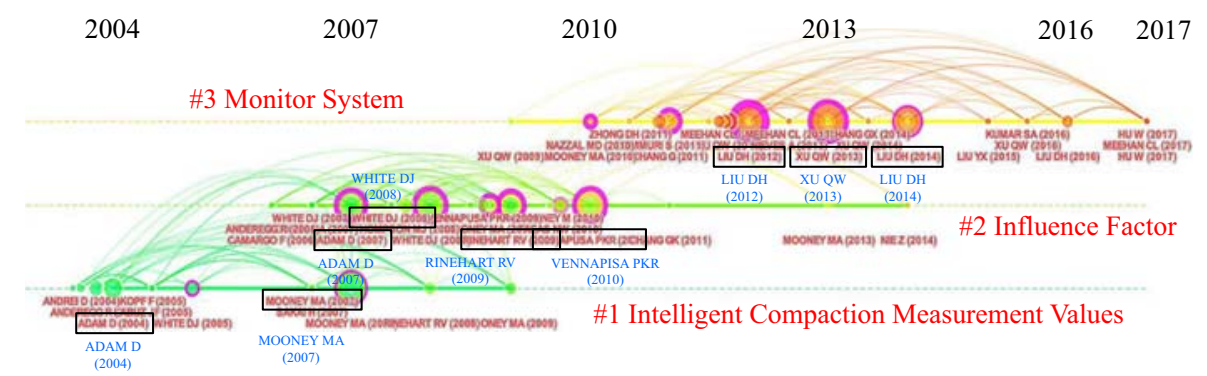

Figure 8.

Timeline view of co-citation clusters

\begin{tabular}{llccc}
\hline Cluster & Paper & Citation frequency & Structural centrality & Half-life \\
\hline 1 & Mooney and Rinehart (2007) & 11 & 0.14 & 2 \\
& Adam and Kopf (2004) & 7 & 0.04 & 5 \\
& White and Thompson (2008) & 10 & 0.24 & 4 \\
& Vennapusa et al. (2010) & 10 & 0.35 & 3 \\
& Adam (2007) & 9 & 0.22 & 3 \\
& Rinehart and Mooney (2009) & 8 & 0.34 & 4 \\
& Xu and Chang (2013) & 12 & 0.21 & 6 \\
& Liu et al. (2012) & 10 & 0.48 & 3
\end{tabular}

Table VIII.

Detection results of the key nodes analysis 
ECAM

27,5

1226

material properties and roller operation status on ICMVs. Vennapusa (Vennapusa et al., 2010) introduced geostatistics to quantitatively evaluate compaction uniformity. Adam (Adam et al., 2007) introduced the specifications and recommendations about the ISSMGE TC3; Rinehart (Rinehart and Mooney, 2009) discussed the triaxial stress-strain properties of the soils beneath the roller. Despite their contributions, a unified knowledge of recommendations was difficult to be built.

Cluster no. 3 was built on the basis of clusters nos 1 and 2. According to the citation analysis, a general post-processing software (Veta) (Xu and Chang, 2013) and an integrated compaction management system that oriented to all users (RMSCQ) (Liu et al., 2012, 2014) were identified as two widely accepted systems. However, IC data are currently underused, so stakeholders may lose a huge opportunity to create additional benefits.

Three hotspots were identified from the co-citation network of IC terms in the past three years, i.e. ICMV applicability, control methods and IC applications (see Figure 9). These findings were helpful in summarizing the issues that hinder the IC technology from being further applied, which will be discussed in Section 3.

\section{Existing problems}

\subsection{ICMV applicability}

Vibratory compaction is a non-linear, and multielement-coupled system that involves many complex issues such as the contacting status, vibration, bouncing and impact. Since there are still no satisfactory theoretical solutions to the ICMV dynamic model, current IC practices rely on a trial test to calibrate ICMVs before they can be applied to the project for compaction quality assessment (FHWA, 2017).

In addition, existing IC products fail to decouple the impact of phase lags, underlying surface, moisture, lift thickness, parameter variation, and operation status. As a result, current ICMVs are overall measurements of the stiffness of the multiple layers beneath the roller, rather than just reflect the compaction quality of a single layer.

Conventional in situ tests have different test principles comparing to ICMVs. The former uses the density of limited discrete samples to represent the compaction quality of the entire working zone, while the latter evaluates the composite stiffness of the compacted materials in the measurement range, and is influenced by regional stress redistribution. In practice, it is difficult to strictly control the roller trajectory, which often results in many overlapped regions in the working zone. These overlapped regions are compacted with more passes than other regions, and thus the non-uniformity of the compacted materials is enlarged. Since ICMVs have limited resolution, the non-uniformity is difficult to be characterized.

\subsection{Control methods}

Currently, it is still difficult for existing IC products to realize fully autonomous control without any human intervention. Although these products offer basic functionalities on adaptive control of the "double jump" and path planning, many advanced autonomous control techniques, such as resonant adjustment, are still under development. For mega projects with large working zones, current IC techniques oriented to single roller control will not be suitable for multi-roller operation scenarios. As a result, the collaborative control of multiple rollers should be further investigated in the future.

\subsection{Specifications and applications}

The acceptance and application of IC in construction practice need to be further promoted (Yoon et al., 2018). Except for the applicability of ICMVs, there are other factors that hinder the advantages of IC technology from being fully utilized. First, existing specifications fail to provide a clear guideline and standard procedure to guide the QC/QA under IC circumstances. 
(a)

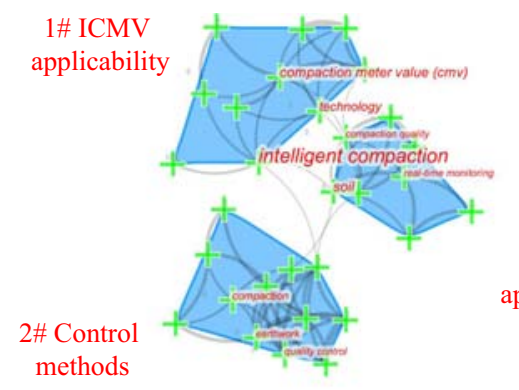

(b)

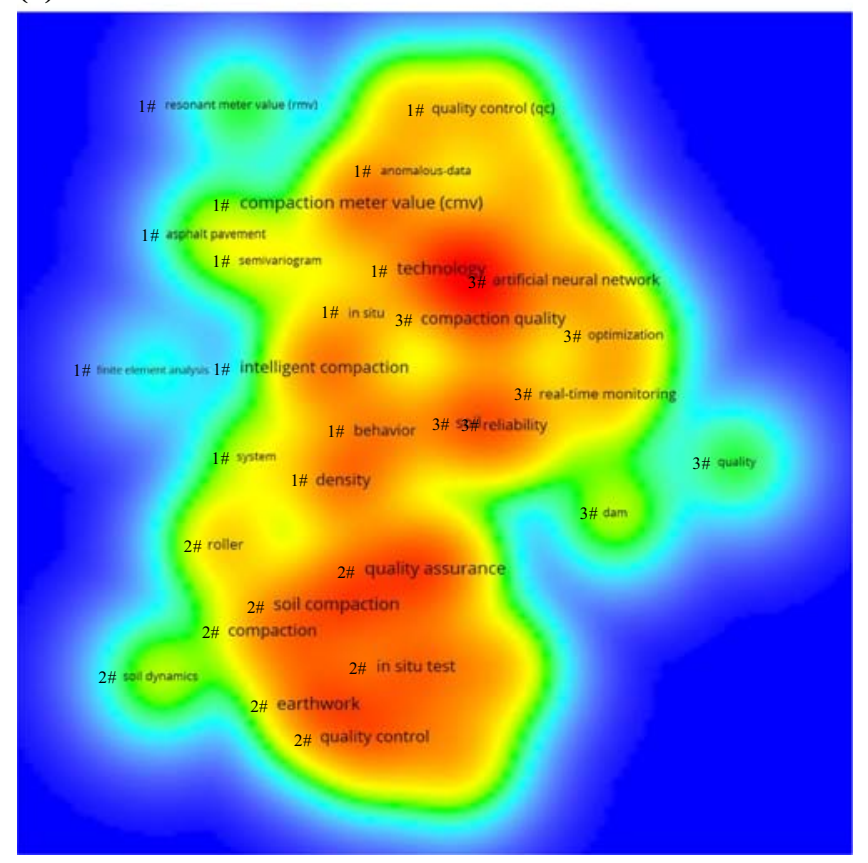

Notes: (a) Clusters; (b) frequency (2016-2018)

Figure 9. Hotspots of IC studies

Second, most owners lack a strong motivation to adopt advanced construction technologies when dispensable. Third, the high applications cost and the unclear profit model in the life cycle deters many contractors from adopting the technology.

\section{Conclusions and recommendations}

Although the IC has been developed for many years, the technology still needs to be further promoted to mitigate its uneven applications in different countries and regions. Currently, the IC practice is confronted with the issues of ICMV applicability, autonomous control, specifications and applications. To address the above issues, potential solutions are recommended as follows:

(1) Considering the uncertain ICMV applicability, a comprehensive ICMV measurement system is required for single layer analysis. To achieve this goal, a simple and 
ECAM

27,5

1228

tractable mathematical representation of the complex compaction dynamics can serve as a preliminary step toward the development of a closed-loop control model for the compaction process. By means of Parallel Code based on OpenMP directive, the dynamic correction based on back-calculated parameters may be available with the limited resources. A comprehensive evaluation based on machine learning algorithms with prior knowledge is also a good solution to predict and obtain layerspecific mechanical and physical properties of the compacted materials. In addition, the position compensation and equivalent transformation between the ICMVs and acceptance testing at random locations can be helpful in the development of the ICMV measurement system to improve their correlation.

(2) In terms of control methods, future studies should focus on the development of autonomous control mechanisms with integrated management capabilities that can collaborate all stakeholders efficiently. Combined with AI-assisted decision information system based on massive data, a higher level of autonomous control can be realized. The typical structure of such autonomous systems might include a truly-unmanned control module that can cope with the complicated construction environment, a powerful information integration system that can provide personalized services involving massive heterogeneous data for all stakeholders, and an interactive collaborative control interface as an intelligent assistant that can optimize the construction process oriented to various engineering machineries.

(3) In terms of the problem in specifications and applications, it is necessary to build a standardized application workflow and the cost-benefit evaluation of IC in the context of the full life cycle. For the government sector, a standardized application workflow based on ample solid evidence can be helpful to standardize the construction market. As a result, the support from the government for basic studies should be emphasized. For stakeholders, remarkable benefits are more attractive. The correct guidance should highlight the potential value of IC technology in the context of full life cycle. A cost-benefit evaluation system for the full life cycle can help the users form the knowledge of IC technology with an objective standard about the evaluation of its necessity. Therefore, the improvement of the utilization level of IC data and the adjustment of project management considering IC technology during the construction phase are also interesting future research topics.

$\begin{array}{ll}\text { Glossary } & \\ \text { ACE } & \text { Ammann compaction expert } \\ \text { AFC } & \text { Auto-feedback control } \\ \text { AI } & \text { Artificial intelligence } \\ \text { BCM } & \text { BOMAG compaction management } \\ \text { CAWDS } & \text { Continuous compaction control acoustic wave detection system } \\ \text { CCV } & \text { Compaction control values } \\ \text { CDS } & \text { Compaction documentation system } \\ \text { CF } & \text { Crest factor } \\ \text { CI } & \text { Compaction index } \\ \text { CIS } & \text { Compaction information system } \\ \text { CMS } & \text { Compaction monitoring system } \\ \text { CMV } & \text { Compaction meter value } \\ \text { CRICOM } & \text { Computer integrated road construction of compaction } \\ \text { CSD } & \text { Contact stress distribution } \\ \text { CTS } & \text { Compactor tracking system }\end{array}$




$\begin{array}{ll}\text { COV } & \text { Coefficient of variation } \\ \text { DCA } & \text { Dynapac compaction analyzer } \\ F_{t} & \text { Turbulence factor } \\ \text { HEMS } & \text { High-embankment monitoring system } \\ \text { ICA } & \text { Intelligent compaction analyzer } \\ \text { MDP } & \text { Machine drive power } \\ \text { OMV } & \text { Oscillometer value } \\ \text { RMSCQ } & \text { Real-time monitoring system for compaction quality } \\ \text { RMV } & \text { Resonance meter value } \\ \text { SCAN } & \text { Soil compaction analysis software } \\ \text { SCV } & \text { Sound compaction value } \\ \text { THD } & \text { Total harmonic distortion } \\ \text { VCV } & \text { Vibrating compaction value } \\ \text { WoS } & \text { Web of Science }\end{array}$

Intelligent compaction analyzer

Machine drive power

Oscillometer value

Resonance meter value

Soil compaction analysis software

Sound compaction value

Vibrating compaction value

Web of Science

\section{References}

Adam, D. and Kopf, F. (2004), "Operational devices for compaction optimization and quality control - (continuous compaction control \& light falling weight device)", in Correia, A.G. and Loizos, A. (Eds), International Seminar on Geotechnics in Pavement and Railway Design and Construction, Mill Press, Rotterdam, pp. 97-106.

Adam, D., Momoya, Y., Correia, A.G., Correia, A.G., Momoya, Y. and Tatsuoka, F. (2007), "Roller integrated continuous compaction control (CCC) technical contractual provisions and recommendations", Design and Construction of Pavements and Rail Tracks: Geotechnical Aspects and Processed Materials, Taylor \& Francis Group, London, pp. 111-138.

Anderegg, R. and Kaufmann, K. (2004), "Intelligent compaction with vibratory rollers - feedback control systems in automatic compaction and compaction control", Transportation Research Record, No. 1868, pp. 124-134.

Anderegg, R., von Felten, D.A. and Kaufmann, K. (2006), “Compaction monitoring using intelligent soil compactors”, in DeGroot, D.J., DeJong, J.T., Frost, D. and Baise, L.G. (Eds), GeoCongress 2006: Geotechnical Engineering in the Information Technology Age, American Society of Civil Engineers, Reston, pp. 1-6.

Beainy, F., Commuri, S. and Zaman, M. (2012), "Quality assurance of hot mix asphalt pavements using the intelligent asphalt compaction analyzer", Journal of Construction Engineering and Management, Vol. 138 No. 2, pp. 178-187.

Cai, J., Gao, Q., Chun, H., Cai, H. and Nantung, T. (2019), "Spatial autocorrelation in soil compaction and its impact on earthwork acceptance testing", Transportation Research Record, Vol. 2673 No. 1, pp. 332-342.

Caterpillar (2007), "AccuGrade”, available at: www.plmcat.com/docs/default-source/custom-equipmentsolutions/accugrade-brochure-in-english.pdf?sfvrsn=e31f0958_0 (accessed October 31, 2018).

Chen, C. (2016), CiteSpace: A Practical Guide for Mapping Scientific Literature, Nova Science Publishers, New York, NY.

Dynapac (2003), "DYNAPAC compaction equipment compaction analyzer", available at: www.ulfia.se/ pdf/VFDCAEN1.pdf (accessed October 31, 2018).

Facas, N.W. and Mooney, M.A. (2012), "Characterizing the precision uncertainty in vibratory roller measurement values", Journal of Testing and Evaluation, Vol. 40 No. 1, pp. 43-51.

Facas, N.W., van Susante, P.J. and Mooney, M.A. (2010), "Influence of rocking motion on vibratory rollerbased measurement of soil stiffness", Journal of Engineering Mechanics, Vol. 136 No. 7, pp. 898-905.

FHWA (2017), "Intelligent compaction measurement values (ICMV)", available at: www.fhwa.dot.gov/ construction/ictssc/pubs/hif17046.pdf (accessed October 31, 2018). 
ECAM

27,5

Furuya, H. and Fujiyama, T. (2011), “Development of soil stiffness evaluation equipment 'Alfa-system' using acceleration response of vibratory roller", 28th International Symposium on Automation and Robotics Construction, International Association for Automation \& Robotics in Construction, Seoul, pp. 337-342.

Graettinger, A.J., Doherty, W.B., Herron, M., Siekmeier, J. and Petersen, L. (2012), "Locating soil tests with intelligent compaction data and geographic information system technology", Transportation Research Record, No. 2310, pp. 10-17.

Hu, W., Huang, B., Shu, X. and Woods, M. (2017), "Utilising intelligent compaction meter values to evaluate construction quality of asphalt pavement layers", Road Materials and Pavement Design, Vol. 18 No. 4, pp. 980-991.

Hua, T., Yang, X., Yao, Q. and Li, H. (2018), "Assessment of real-time compaction quality test indexes for rockfill material based on roller vibratory acceleration analysis", Advances in Materials Science and Engineering, Vol. 2018, pp. 1-15.

Hwang, J., Yun, H., Kim, J., Suh, Y., Hong, S. and Lee, D. (2012), "Development of soil compaction analysis software (SCAN) integrating a low cost GPS receiver and compactometer", Sensors, Vol. 12 No. 3, pp. 2351-2372.

Kassem, E., Liu, W., Scullion, T., Masad, E. and Chowdhury, A. (2015), "Development of compaction monitoring system for asphalt pavements", Construction and Building Materials, Vol. 96, pp. 334-345.

Kassem, E., Scullion, T., Masad, E. and Chowdhury, A. (2012), "Comprehensive evaluation of compaction of asphalt pavements and a practical approach for density predictions", Transportation Research Record, Vol. 2268, pp. 98-107.

Kimmel, S.C. and Mooney, M.A. (2011), "Real-time soil compaction monitoring through pad strain measurements: modeling to inform strain gage placement", SPIE 7981, Sensors and Smart Structures Technologies for Civil, Mechanical, and Aerospace Systems 2011, The International Society for Optics and Photonics, Bellingham, pp. 79815F-1-7.

Kloubert, H.J. (2006), "Intelligent soil and asphalt compaction technology", 85th TRB Annual Meeting, Transportation Research Board, Washington, DC, pp. 1-10.

Krishnamurthy, B.K., Tserng, H., Schmitt, R.L., Russell, J.S., Bahia, H.U. and Hanna, A.S. (1998), "AutoPave: towards an automated paving system for asphalt pavement compaction operations", Automation in Construction, Vol. 8 No. 2, pp. 165-180.

Kuenzel, R., Teizer, J., Mueller, M. and Blickle, A. (2016), "SmartSite: intelligent and autonomous environments, machinery, and processes to realize smart road construction projects", Automation in Construction, Vol. 71, pp. 21-33.

Liu, D. and Gao, L. (2018), "Analysis and improvement of roller vibration behavior-based indexes for monitoring compaction quality of earth-rock dams", Journal of Hydroelectric Engineering, Vol. 37 No. 4, pp. 111-128 (in Chinese).

Liu, D., Li, Z. and Lian, Z. (2014), "Compaction quality assessment of earth-rock dam materials using roller-integrated compaction monitoring technology", Automation in Construction, Vol. 44, pp. 234-246.

Liu, D., Li, Z. and Liu, J. (2015), "Experimental study on real-time control of roller compacted concrete dam compaction quality using unit compaction energy indices", Construction and Building Materials, Vol. 96, pp. 567-575.

Liu, D., Lin, M. and Li, S. (2016), "Real-time quality monitoring and control of highway compaction", Automation in Construction, Vol. 62, pp. 114-123.

Liu, D., Song, J., Zhong, D. and Song, L. (2012), "Compaction quality control of earth-rock dam construction using real-time field operation data", Journal of Construction Engineering and Management, Vol. 138 No. 9, pp. 1085-1094.

Meehan, C.L., Cacciola, D.V., Tehrani, F.S. and Baker, W.J. (2017), "Assessing soil compaction using continuous compaction control and location-specific in situ tests", Automation in Construction, Vol. 73, pp. 31-44. 
Minchin, R.E., Swanson, D.C., Gruss, A.F. and Thomas, H.R. (2008), "Computer applications in intelligent compaction", Journal of Computing in Civil Engineering, Vol. 22 No. 4, pp. 243-251.

Mooney, M.A. and Rinehart, R.V. (2007), "Field monitoring of roller vibration during compaction of subgrade soil", Journal of Geotechnical and Geoenvironmental Engineering, Vol. 133 No. 3, pp. 257-265.

Mooney, M.A. and Rinehart, R.V. (2009), "In situ soil response to vibratory loading and its relationship to roller-measured soil stiffness", Journal of Geotechnical and Geoenvironmental Engineering, Vol. 135 No. 8, pp. 1022-1031.

Mooney, M.A., Gorman, P.B. and Gonzalez, J.N. (2005), "Vibration-based health monitoring of earth structures”, Structural Health Monitoring-an International Journal, Vol. 4 No. 2, pp. 137-152.

Nie, Z., Jiao, T., Wang, X. and Qiu, T. (2018), "Assessment of compaction quality based on two index parameters from roller-integrated compaction measurements", Journal of Testing and Evaluation, Vol. 46 No. 1, pp. 428-433.

Oloufa, A.A. (2002), "Quality control of asphalt compaction using GPS-based system architecture", IEEE Robotics and Automation Magazine, Vol. 9 No. 1, pp. 29-35.

Pampagnin, L.H., Peyret, F. and Garcia, G. (1998), “Architecture of a GPS-based guiding system for road compaction”, The 1998 IEEE International Conference on Robotics \& Automation, Institute of Electrical and Electronics Engineers, Piscataway, pp. 2422-2427.

Pistrol, J. and Adam, D. (2018), "Fundamentals of roller integrated compaction control for oscillatory rollers and comparison with conventional testing methods", Transportation Geotechnics, Vol. 17, pp. $75-84$.

Rinehart, R.V. and Mooney, M.A. (2009), "Measurement of roller compactor induced triaxial soil stresses and strains", Geotechnical Testing Journal, Vol. 32 No. 4, pp. 347-357.

Rinehart, R.V., Mooney, M.A., Facas, N.F. and Musimbi, O.M. (2012), "Examination of roller-integrated continuous compaction control on colorado test site", Transportation Research Record, No. 2310, pp. 3-9.

Sakai (2018), "Intelligent compaction", available at: www.sakaiamerica.com/technology/intelligentcompaction (accessed October 31, 2018).

Schmitt, R.L. (2012), “AAPT Symposium: layer thickness, compaction temperatures, and achieving density", 2012 Association of Asphalt Paving Technologists Annual Meeting, Association of Asphalt Paving Technologists, Lino Lakes, pp. 761-764.

Singh, D., Beainy, F., Commuri, S. and Zaman, M. (2015), “Application of intelligent compaction technology for estimation of effective modulus for a multilayered asphalt pavement", Journal of Testing and Evaluation, Vol. 43 No. 2, pp. 308-318.

Thurner, H.F. and Sandstrom, A. (2000), "Continuous compaction control, CCC", European Workshop Compaction of Soils and Granular Materials, Presses Ponts et Chaussées, Paris, pp. 237-246.

Vennapusa, P.K.R., White, D.J. and Morris, M.D. (2010), "Geostatistical analysis for spatially referenced roller-integrated compaction measurements", Journal of Geotechnical and Geoenvironmental Engineering, Vol. 136 No. 6, pp. 813-822.

Veta (2018), "Veta introduction", available at: www.intelligentconstruction.com (accessed October 31, 2018).

Wang, J., Li, X., Christakos, G., Liao, Y., Zhang, T., Gu, X. and Zheng, X. (2010), "Geographical detectors-based health risk assessment and its application in the neural tube defects study of the Heshun region, China”, International Journal of Geographical Information Science, Vol. 24 No. 1, pp. 107-127.

White, D.J. and Thompson, M.J. (2008), "Relationships between in situ and roller-integrated compaction measurements for granular soils", Journal of Geotechnical and Geoenvironmental Engineering, Vol. 134 No. 12, pp. 1763-1770.

$\mathrm{Xu}$, Q. and Chang, G.K. (2013), "Evaluation of intelligent compaction for asphalt materials", Automation in Construction, Vol. 30, pp. 104-112. 
ECAM

27,5
Xu, Q. and Chang, G.K. (2016), "Adaptive quality control and acceptance of pavement material density for intelligent road construction”, Automation in Construction, Vol. 62, pp. 78-88.

Yan, Z., Du, D., Liu, C., Gui, Q. and Yang, W. (2018), "Visualization analysis of mapping knowledge domain on Western geography of innovation", Acta Geographica Sinica, Vol. 73 No. 2, pp. 362-379 (in Chinese).

Yao, Y., Ruan, Y., Chen, J., Geng, Y., Zhang, X., Liu, B., Zong, X. and Yu, G. (2018), "Research on a real-time monitoring platform for compaction of high embankment in airport engineering", Journal of Construction Engineering and Management, Vol. 144 No. 1, pp. 1-10.

Yoon, S., Hastak, M. and Lee, J. (2018), "Suitability of intelligent compaction for asphalt pavement quality control and quality assurance", Journal of Construction Engineering and Management, Vol. 144 No. 4, pp. 1-8.

Zhang, J., Xu, G. and Cai, Y. (2015), "An investigation on quality inspection and control for continuously compacting subgrade", Rock and Soil Mechanics, Vol. 36 No. 4, pp. 1141-1146 (in Chinese).

Zhang, Q., Liu, T. and Li, Q. (2017), "Roller-integrated acoustic wave detection technique for rockfill materials", Applied Sciences, Vol. 7 No. 11, pp. 1-21.

Zhu, X., Bai, S., Xue, G., Yang, J., Cai, Y., Hu, W., Jia, X. and Huang, B. (2018), "Assessment of compaction quality of multi-layer pavement structure based on intelligent compaction technology", Construction and Building Materials, Vol. 161, pp. 316-329.

\section{Further reading}

Facas, N.W. and Mooney, M.A. (2010), "Position reporting error of intelligent compaction and continuous compaction control roller-measured soil properties", Journal of Testing and Evaluation, Vol. 38 No. 1, pp. 13-18.

\section{Corresponding author}

Donghai Liu can be contacted at: liudh@tju.edu.cn

For instructions on how to order reprints of this article, please visit our website: 